\title{
Ras and Raf pathways in epidermis development and carcinogenesis
}

\author{
F Kern', T Niault ${ }^{1,2}$ and M Baccarini, ${ }^{*}, 1$ \\ 'University of Vienna, Center for Molecular Biology, Max F. Perutz Laboratories, Doktor-Bohr-Gasse 9, A- 030 Vienna, Austria
}

\begin{abstract}
The epidermis is the outermost layer of the body and protects it from environmental insults. This crucial function is sustained by a continuous process of self-renewal involving the carefully balanced proliferation and differentiation of progenitor cells constantly replacing the mature cells at the surface of the epidermis. Genetic changes in the signalling pathways controlling keratinocyte proliferation and differentiation disrupt this balance and lead to pathological changes including carcinogenesis. This review discusses the role of Ras, an oncogene critically involved in the development of skin neoplasia, and its downstream effector Raf in epidermal homeostasis and tumourigenesis. In particular, we will focus on the recently established role of Raf-I as the decisive element that, by restraining keratinocyte differentiation, allows the development and maintenance of Ras-driven tumours.
\end{abstract}

British Journal of Cancer (20II) I 04, 229-234. doi: I0.1038/sj.bjc.6606009 www.bjcancer.com

Published online 16 November 2010

(c) 20II Cancer Research UK

Keywords: Raf kinases; Ras pathway; epidermal development; carcinogenesis; differentiation therapy

The epidermis is the outer layer of the skin, a stratified squamous epithelium that forms a protective barrier against environmental insults and prevents body dehydration. The epidermis is primarily composed of keratinocytes in which pigment cells (melanocytes), immune cells (Langerhans cells and T cells) and nerve-ending cells (Merkel cells) are embedded. Invaginating into the dermis, the epidermis gives rise to various appendages: the hair, produced by the hair follicles, the sebaceous glands that lubricate the skin and the sweat glands that extrude water and salts (Figure $1 \mathrm{~A}$ ). The epidermis is separated from the dermis by the basement membrane, which is rich in extracellular matrix, and is organised into four major layers: the stratum basale, the stratum spinosum, the stratum granulosum and the stratum corneum. The stratum basale contains the keratinocyte progenitors required for skin renewal. These can either divide to generate further progenitor or give rise to suprabasal keratinocytes (reviewed in Blanpain and Fuchs, 2009). As they progress to the stratum spinosum and to the stratum granulosum, the keratinocytes produce the network of keratin filaments anchored in intercellular junctions that provide structural support to the skin; the cells flatten and exocytose lamellar granules containing the precursors of the lipids that contribute to the stratum corneum barrier. The stratum corneum contains the last stage of differentiation, the enucleated corneocytes, which are continuously sloughed off and must be replaced by differentiation of the lower layers (Figure 1B).

To preserve the integrity of the epidermal barrier, the epidermis turns over throughout life. Alterations in this process, such as

\footnotetext{
*Correspondence: Professor M Baccarini; E-mail: manuela.baccarini@univie.ac.at ${ }^{2}$ Current address: Microbes and Host Barriers Group, Inserm Avenir U604, Institut Pasteur, 25 Rue du Docteur Roux, 75724 Paris Cedex 15 , France

Received 5 July 2010; revised 20 October 2010; accepted 22 October 2010 ; published online 16 November 2010
}

keratinocyte proliferation/differentiation defects, or inflammation can lead to cancer or skin barrier defects; thus, the many signalling pathways involved in epidermal homeostasis must be tightly controlled.

\section{RAS PATHWAYS IN THE EPIDERMIS}

The epidermal growth factor receptor (EGFR) is a critical regulator of epidermal homeostasis (Figure 1C). Binding of EGFR to its ligands, EGF, TGF- $\alpha$ and IGF, promotes keratinocyte proliferation; in contrast, inhibitory ligands of EGFR, Lrig1 and Mig6 are involved in maintaining stem cell quiescence, as ablation of either protein leads to hyperproliferation of keratinocytes (Fuchs, 2009). Downstream of EGFR, activation of Ras induces keratinocyte proliferation and inhibits differentiation (Khavari and Rinn, 2007). Ras isoforms are small G-nucleotide-binding proteins that oscillate between a GDP-bound, inactive state, and a GTP-bound state in which they can bind and activate their downstream effectors. In growth factor signalling, the transition between the inactive and the activated state is engendered by the binding of a guanine nucleotide exchange factor (GEF) that displaces GDP. Once GDP is displaced, GTP, whose intracellular concentration is ten-fold higher than that of GDP, will bind to Ras, converting it into an active form. Active Ras will then proceed to stimulate a number of effectors, including the prominent classical effectors phosphoinositide-3 kinase (PI-3K) and Raf; Ral-GDS and Tiam-1, exchange factors leading to the activation of small GTPases Ral and Rac; and several other less well-defined effectors (Figure 1C; Karnoub and Weinberg, 2008). These molecules control aspects of keratinocyte biology ranging from the regulation of proliferation, traditionally attributed to the Raf/MEK/ERK pathway (see below), or of survival, linked to the activation of PI-3K and its downstream target Akt (Sibilia et al, 2000; Calautti et al, 2005) and Ral-GDS (Gonzalez-Garcia et al, 2005), to the establishment of cell-cell 
A

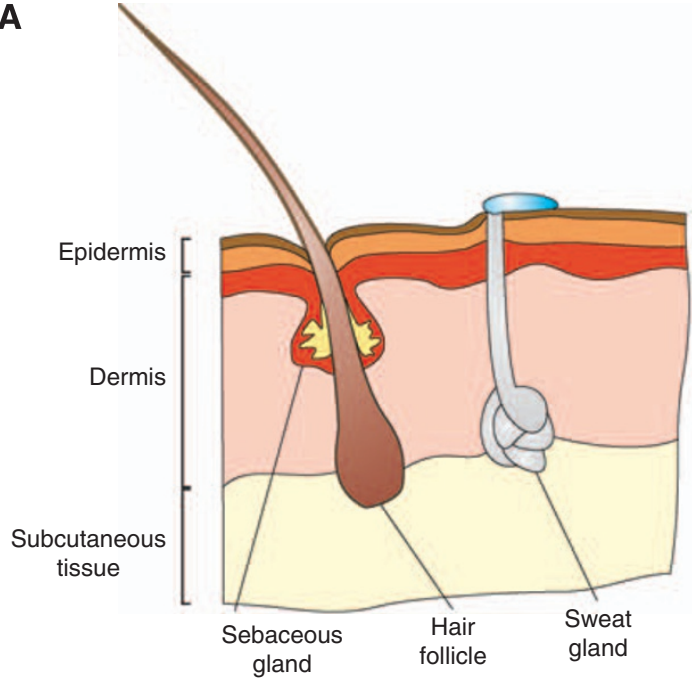

C
$\mathbf{B}$

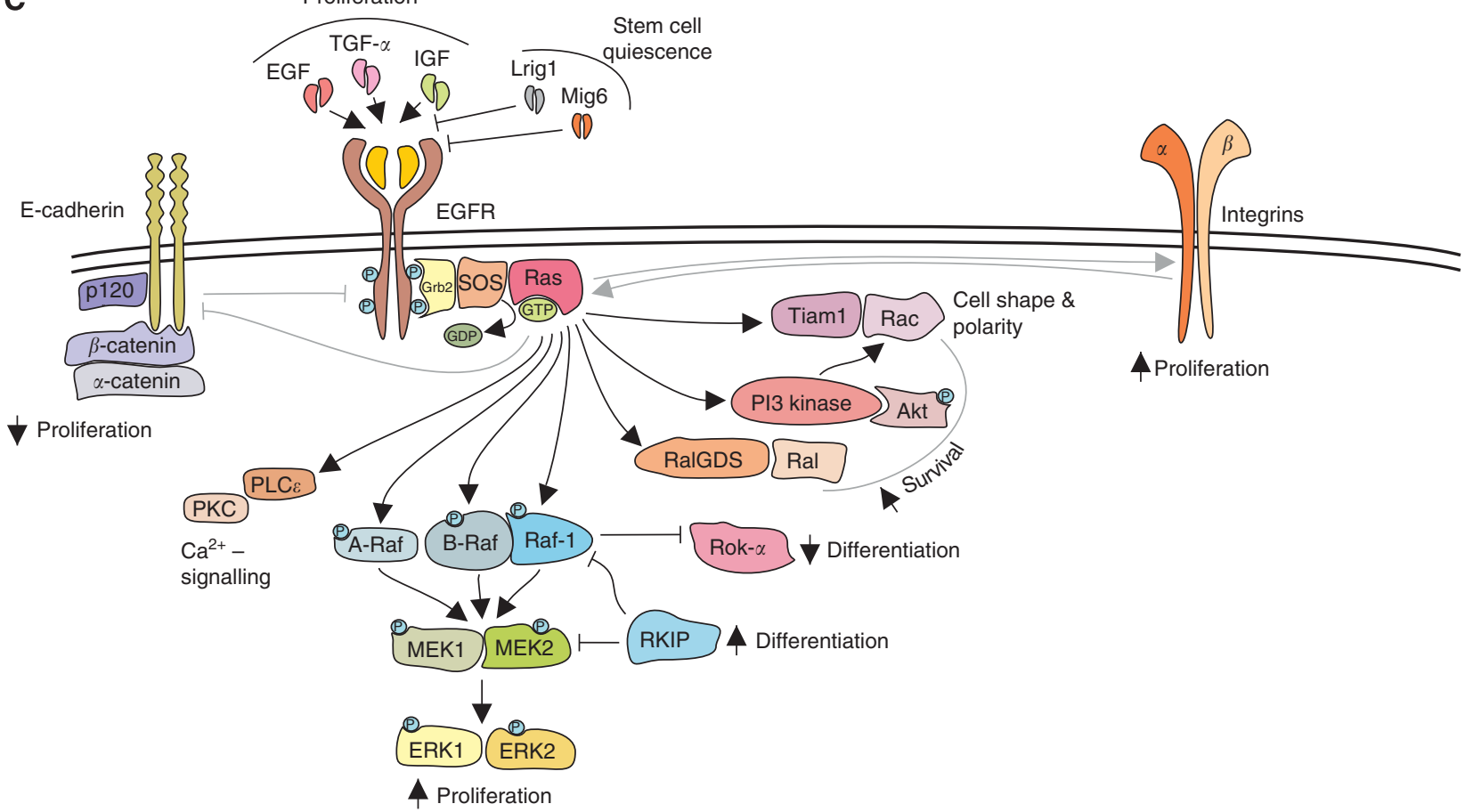

Figure I Ras pathways in the epidermis. (A) Schematic representation of mammalian skin. The skin consists of subcutaneous tissue, dermis and epidermis. Hair follicles and sebaceous glands invaginate into the dermis. (B) Structure of the epidermis. The epidermis is mainly composed of keratinocytes in various stages of differentiation. We distinguish four strata: the stratum basale, comprising the proliferating, undifferentiated basal keratinocytes; the strata spinosum and granulosum, containing differentiating keratinocytes; and the stratum corneum, with the terminally differentiated, enucleated corneocytes that are continuously removed and replaced by cells from the differentiating strata below. (C) The Ras pathway in the epidermis. Ras can be activated downstream of the EGFR and integrins, and can be inhibited by adhesion molecules, such as E-cadherins, inducing growth arrest. With its host of downstream effectors, Ras can mediate survival, proliferation, and can inhibit differentiation (see text for details). Arrows denote induction, blunt arrows indicate inhibition. Arrows pointing upwards signify increase, and arrows pointing downwards symbolise decrease.

adhesion, polarity and redox balance, controlled by Tiam1 (Mertens et al, 2005; Pegtel et al, 2007; Rygiel et al, 2008). Thus, activation of the Ras pathway by growth factors must be kept under tight control to provide just the right balance of proliferation/differentiation signals required for epidermal homeostasis.

Adhesion molecules, such as integrins and cadherins, have a crucial role in the modulation of growth factor signalling in the epidermis. In general, integrin activation supports proliferation, whereas cadherins can both support or inhibit it (Figure 1C); E-cadherin and desmosomal cadherins, for instance, modulate the
EGF response to signal growth arrest (Muller et al, 2008). In line with its crucial role in proliferative signalling, the Ras pathway is activated by integrins (Janes and Watt, 2006) and negatively regulated by cell-cell adhesion: ablation of either $\alpha$-catenin or p120-catenin in the epidermis causes a reduction of adherens junctions, which does not affect skin barrier and intercellular adhesion but leads to hyperplasia and to sustained activation of the Ras/ERK pathway (Vasioukhin et al, 2001; Perez-Moreno et al, 2006).

Activating Ras mutations stabilise this signalling-competent, GTP-bound state. These mutations are frequent in human cancer 
(33\%; higher frequency in epithelial cancers and melanoma; http:// www.sanger.ac.uk/genetics/CGP/cosmic). The number of tumours (particularly squamous cell carcinomas) containing GTP-bound Ras is however much higher, likely owing to the autocrine/ paracrine activation and/or to mutation in receptor tyrosine kinases such as the EGFR (Khavari and Rinn, 2007). Expression of constitutively active Ras mutants in the basal layer of mouse epidermis induces proliferation and inhibits differentiation (Vitale-Cross et al, 2004; Khavari and Rinn, 2007); the activation of endogenous Ras by the transgenic expression of the Ras GEFs SOS (Sibilia et al, 2000) and Rasgrp1 (Oki-Idouchi and Lorenzo, 2007) in the same epidermal compartment produces similar phenotypes. Consistent with an essential role of Ras in skin tumourigenesis, H-Ras ablation impairs tumour development in mouse models of chemical carcinogenesis (Ise et al, 2000).

The consequences of Ras activation in the epidermis can be mimicked, at least in part, by the expression of gain-of-function mutants of Ras downstream effectors. Constitutively active Akt mutants promote proliferation in skin (Murayama et al, 2007); conversely, the knock-in of a PI-3K mutant incapable of binding to Ras reduces tumour load in a chemical model of epidermal carcinogenesis (Gupta et al, 2007). Ablation of other Ras targets such as Tiam1 (Malliri et al, 2002) and its downstream target Rac1 (Wang et al, 2010), Ral-GDS (Gonzalez-Garcia et al, 2005) and PLCepsilon (Bai et al, 2004) has similar effects, but only in the case of Racl it is clear that the phenotype is cell autonomous.

\section{RAF PATHWAYS IN THE EPIDERMIS}

The Raf/MEK/ERK cascade is the longest-studied and probably the best-described Ras effector pathway. The term 'cascade' already suggests the chain reaction that propels the signal, in the form of sequential phosphorylation, from an entry point to an intermediate kinase and finally to ERK, the business end of the pathway. ERK stimulation results in the phosphorylation of transcription factors, structural proteins and metabolic enzymes, and ultimately engenders both short- and long-term changes in cellular behaviour. This basic three-tiered module is robust and plastic at the same time, allowing not only the amplification but also the diversification and temporal modulation of the signal at each and every node; in mammals, it is found in four mitogen-activated protein kinase (MAPK) pathways that contribute to implementing biological outcomes as diverse as proliferation, apoptosis, differentiation, motility and response to stress and cytokines.

One outstanding feature of the Raf/MEK/ERK pathway in mammals is redundancy. Mammals have three Raf isoforms (A-Raf, B-Raf and Raf-1, also known as C-Raf), two MEK and two ERK isoforms. All three Rafs can bind to Ras and phosphorylate MEK, although B-Raf is much more efficient than the other two and is necessary for ERK activation in vivo (reviewed in GalabovaKovacs et al, 2006a; Niault and Baccarini, 2010). Both MEKs can phosphorylate ERK1/2; and whether ERK1/2 have non-redundant functions or not is still unclear (see below).

Consistent with its prominent role as a MEK kinase, B-Raf is the component of the ERK pathway most often mutated in human tumours, with a particularly high frequency $(43 \%)$ in human melanoma. The most frequent B-Raf mutation, V600E, results in constitutive catalytic activity and MEK/ERK activation. Recently, a kinase drug selectively inhibiting B-Raf V600E has achieved an unprecedented response rate of $80 \%$ in phase 1 clinical trials involving metastatic melanoma patients, opening new therapeutic avenues for this deadly disease (Bollag et al, 2010; Flaherty et al, 2010). Less frequent BRAF mutations reduce intrinsic catalytic activity but drive MEK/ERK activation by stimulating the formation of B-Raf/Raf-1 heterodimers in which mutant B-Raf activates wild-type Raf-1 in trans (reviewed in Niault and Baccarini, 2010; Wimmer and Baccarini, 2010).
Unlike B-Raf, Raf-1 is infrequently mutated in human cancer (overall frequency of 1\%; http://www.sanger.ac.uk/genetics/CGP/ cosmic). The rare mutations detected in human cancer cell lines and in patients with therapy-related acute myeloid leukaemia do not drive tumourigenesis per se, but can do so upon somatic loss of a negative regulator of Raf-mediated MEK/ERK activation, the Raf kinase inhibitory protein RKIP (Niault and Baccarini, 2010). Interestingly, RKIP promotes differentiation of human keratinocytes (Yamazaki et al, 2004), and both RKIP and B-Raf are downregulated in human SCC (Zaravinos et al, 2009), whereas Raf-1 is overexpressed (Riva et al, 1995). Mutations or overexpression of MEK or ERK in human SCC have not been reported.

The data summarised above suggest that Raf- 1 is an important player in the development of human SCC. Support for this idea came in the unexpected form of recent findings concerning smallmolecule inhibitors of Raf. These compounds, some of which are already being used in the clinic, efficiently inhibit MEK/ERK activation in cells harbouring the B-Raf V600E mutation (Bollag et al, 2010; Flaherty et al, 2010), but can activate the ERK pathway to different extents in normal cells and in cells expressing Ras mutations. At the molecular level, the inhibitors promote the formation of dimers in which wild-type Raf-1 is activated in trans (reviewed in Brower, 2010; Cichowski and Janne, 2010; Wimmer and Baccarini, 2010). Before these reports, potentially deleterious effects of Raf inhibitors because of ERK inhibition in normal cells were expected to limit their clinical use. In stark contrast, these studies now predict that these inhibitors may be dangerous because they may activate Raf-1 and MEK/ERK in B-Raf wild-type cells prone to deregulated proliferation because of other mutations. Intriguingly, although the inhibitors are administered systemically, keratoacanthomas and SCC in situ develop in patients treated with Raf inhibitors (Brower, 2010; Cichowski and Janne, 2010; Wimmer and Baccarini, 2010), underscoring the connection between Raf-1 activation and epidermal proliferation and tumourigenesis.

The role of the Raf/MEK/ERK pathway in epidermal proliferation has been clearly established in animal models, in which inducible activation of Raf or MEK in the epidermis results in massive cutaneous hyperplasia and reduced differentiation (Khavari and Rinn, 2007). In apparent contrast, knockout of B-Raf (Galabova-Kovacs et al, 2006b), Raf-1 (Ehrenreiter et al, 2005), MEK1, MEK2 (Scholl et al, 2007), ERK1 and ERK2 (Dumesic et al, 2009) has no effect on epidermis development and/or homeostasis. In the MEK and ERK knockouts, this lack of phenotype may result from functional redundancy within the pathway. Indeed, epidermis-restricted compound MEK1/MEK2 knockout causes severe barrier function defects and marked epidermis hypoplasia leading to perinatal death (Scholl et al, 2007); and simultaneous ERK1/ERK2 ablation inhibits keratinocyte division (Dumesic et al, 2009). MEK1/2 gene dosage also appears to be the rate-limiting factor in the hyperplastic response of mouse epidermis to activated Ras (Scholl et al, 2009a); in contrast, however, MEK1 (but not MEK2) and ERK1 are required for full-fledged chemical carcinogenesis (Bourcier et al, 2006; Scholl et al, 2009b). Together, these results confirm the role of the ERK pathway in promoting proliferation and restraining differentiation in the epidermis.

However, recent conditional gene ablation experiments have revealed that one of the Raf kinases has ERK-independent roles in keratinocyte biology and tumourigenesis. As mentioned above, mice harbouring epidermis-restricted Raf-1 ablation do not show any major anomalies, with the exception of a curly fur and whiskers that subside after the first hair cycle. Wound healing, however, is delayed in these mice, and their keratinocytes show defects in adhesion and migration (Ehrenreiter et al, 2005). These phenotypes do not correlate with defects in ERK phosphorylation; rather, we have been able to trace them to the cytoskeleton-based Rho effector Rok- $\alpha$, which is hyperactive in Raf-1-deficient cells (Ehrenreiter et al, 2005, 2009; Niault et al, 2009). 
Although these data do not exclude that Raf-1 may have function(s) connected with its ability to phosphorylate MEK or other substrates, they do indicate that the essential role of Raf-1, at least in the epidermis, is independent of its kinase activity. But what happens if one stresses the system, for instance, by inducing tumourigenesis in vivo? We have answered this question by combining a chemical and a genetic tumourigenesis protocol with epidermis-restricted Raf- 1 ablation in mice. Both models rely on the activation of Ras, caused by mutations in the DMBA/TPA chemical carcinogenesis model (Ise et al, 2000) or by tethering the Ras activator SOS to the membrane of basal keratinocytes (Sibilia et al, 2000); this results in the constitutive activation of endogenous Ras, observed more frequently than Ras mutations in human SCC (Dajee et al, 2003). The results were striking: Raf-1deficient epidermis was completely refractory to tumour formation in both models; in addition, using the genetic model we could show that Raf-1 ablation enforces complete, rapid regression of established lesions that never recur, although Ras activation persists throughout the life of the animals (Figure 2; Ehrenreiter et al, 2009). Tumour regression is characterised by massive, runaway differentiation, which was a surprise in view of the wellestablished role of Raf-1 in proliferation and of its essential antiapoptotic function in other cell types (Galabova-Kovacs et al, 2006a). These data identify Raf-1 as the single key Ras effector absolutely required for both development and maintenance of Rasdriven tumours in vivo. They evoke the concept of 'non-oncogene addiction', intended as the absolute dependence of cancer cells on a non-mutated component of a signalling pathway to prevent system failure in the form of apoptosis or, as in this case, differentiation. Downstream of Ras, activated Raf-1 binds to Rok- $\alpha$, reducing its activity (Figure 2); Rok- $\alpha$, in turn, has been previously implicated in keratinocyte differentiation (McMullan et al, 2003) and, via the phosphorylation of Cofilin, can prevent the activation of the STAT3/Myc axis (Honma et al, 2006).

The relevance of the Raf- $1 /$ Rok- $\alpha$ interaction for tumourigenesis is illustrated by the fact that Ras-driven dedifferentiation, STAT3 phosphorylation and Myc expression occur both in wild-type and in Raf-1-deficient epidermis treated with a chemical Rok inhibitor
(Ehrenreiter et al, 2009). These data establish Raf-1 as an endogenous Rok- $\alpha$ inhibitor operating downstream of Ras to regulate keratinocyte differentiation, and imply that caution is in order when using Rok inhibitors, especially in the treatment of Ras-driven tumours (Figure 2).

Rok- $\alpha$ inhibition by Raf- 1 requires physical interaction between the two proteins. In growth factor-stimulated or Ras-transformed cells, the kinase domain of Rok- $\alpha$ interacts with, and is inhibited by, the regulatory domain of Raf- 1 , which is structurally very similar to Rok- $\alpha$ 's own autoinhibitory domain (Niault et al, 2009). This kind of 'inhibition in trans' has never been reported before, and represents a new paradigm of kinase regulation and pathway cross-talk.

Our results have implications for future therapeutic strategies targeting the Raf-1/Rok- $\alpha$ interaction, for instance, by silencing the Raf-1 gene or by using small-molecule inhibitors to disrupt the complex. The predicted outcome of such interventions is an increase in Rok- $\alpha$ activity, resulting in turn in epithelial cell differentiation. The success of these therapies, however, might be highly context dependent. We must bear in mind that Rok- $\alpha$ was found upregulated in human SSC samples, and that its overexpression confers features of malignancy to human tumours in mouse xenograft models (Lefort et al, 2007). It is possible that treatments aimed at increasing Rok- $\alpha$ activation might be beneficial only in the context of epithelial tumours driven by Ras activation. Alternatively, tumour cells might accumulate mutations, downstream of Rok- $\alpha$ or in other pathways, which enable them to tolerate high Rok- $\alpha$ activity without undergoing differentiation. Thus, as in the case of other approaches, the success of a Rok- $\alpha$ activation therapy might depend both on the type of tumour and on the stage of the tumour at the time of intervention.

\section{CONCLUSIONS}

The evidence summarised above is consistent with a pivotal role of Ras and its downstream effectors in epidermal tumourigenesis. Ras effectors have been reported to induce proliferation and

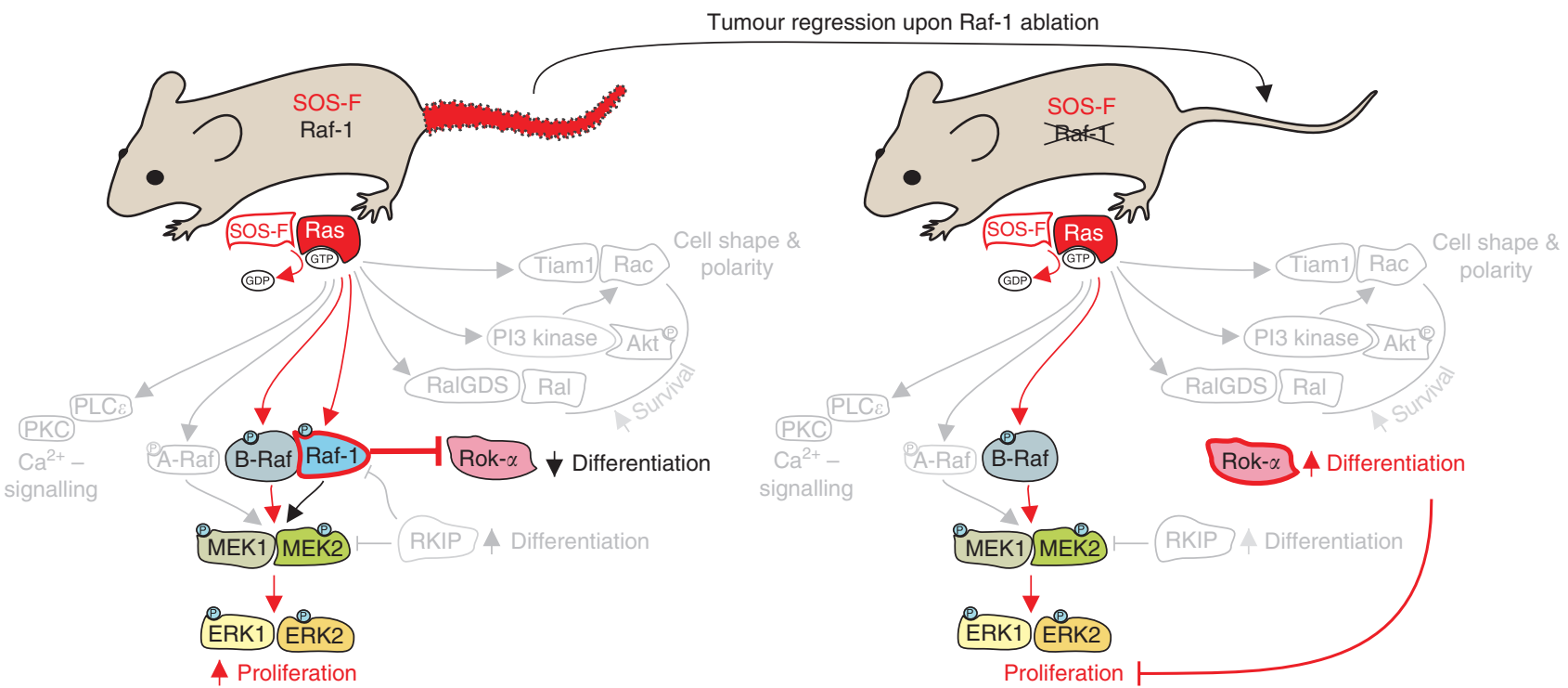

Figure 2 Ras-driven tumours are addicted to Raf-I. Ras-driven tumours, induced by the keratinocyte-restricted expression of membrane-tethered SOS (SOS-F transgenic mice; red, irregularly shaped tail) regress upon keratinocyte-specific ablation of Raf-I, indicating an essential role of this molecule in tumour maintenance. Downstream of Ras, Raf-I is involved in at least two pathways: the canonical Raf/MEK/ERK pathway, where Raf-I acts as an activator, likely in the context of a Ras-induced heterodimer with B-Raf; and the Rok- $\alpha$ pathway, where Raf-I acts as an inhibitor via direct protein-protein interaction (left panel). Upon Raf-I ablation (right panel; Raf-I crossed out), ERK phosphorylation continues undisturbed, likely sustained by B-Raf; Rok- $\alpha$, however, is strongly activated, leading to increased differentiation, and to tumour regression. 
prevent apoptosis; recently, the differentiation block enforced by Raf-1-mediated Rok- $\alpha$ has been added to the potentially 'druggable' events required for Ras-driven tumourigenesis. The prediction of our in vivo work is that freeing Rok- $\alpha$ from its interaction with Raf-1, for instance, by silencing the Raf- 1 gene or by using small-molecule inhibitors aimed to disrupt the complex,

\section{REFERENCES}

Bai Y, Edamatsu H, Maeda S, Saito H, Suzuki N, Satoh T, Kataoka T (2004) Crucial role of phospholipase Cepsilon in chemical carcinogen-induced skin tumor development. Cancer Res 64: 8808-8810

Blanpain C, Fuchs E (2009) Epidermal homeostasis: a balancing act of stem cells in the skin. Nat Rev Mol Cell Biol 10: 207-217

Bollag G, Hirth P, Tsai J, Zhang J, Ibrahim PN, Cho H, Spevak W, Zhang C, Zhang Y, Habets G, Burton EA, Wong B, Tsang G, West BL, Powell B, Shellooe R, Marimuthu A, Nguyen H, Zhang KY, Artis DR, Schlessinger J, Su F, Higgins B, Iyer R, D’Andrea K, Koehler A, Stumm M, Lin PS, Lee RJ, Grippo J, Puzanov I, Kim KB, Ribas A, McArthur GA, Sosman JA, Chapman PB, Flaherty KT, Xu X, Nathanson KL, Nolop K (2010) Clinical efficacy of a RAF inhibitor needs broad target blockade in BRAF-mutant melanoma. Nature 467: 596-599

Bourcier C, Jacquel A, Hess J, Peyrottes I, Angel P, Hofman P, Auberger P, Pouyssegur J, Pages G (2006) p44 mitogen-activated protein kinase (extracellular signal-regulated kinase 1)-dependent signaling contributes to epithelial skin carcinogenesis. Cancer Res 66: 2700-2707

Brower V (2010) BRAF inhibitors: research accelerates in wake of positive findings. J Natl Cancer Inst 102: 214-215

Calautti E, Li J, Saoncella S, Brissette JL, Goetinck PF (2005) Phosphoinositide 3-kinase signaling to Akt promotes keratinocyte differentiation versus death. J Biol Chem 280: 32856-32865

Cichowski K, Janne PA (2010) Drug discovery: inhibitors that activate. Nature 464: 358-359

Dajee M, Lazarov M, Zhang JY, Cai T, Green CL, Russell AJ, Marinkovich MP, Tao S, Lin Q, Kubo Y, Khavari PA (2003) NF-kappaB blockade and oncogenic Ras trigger invasive human epidermal neoplasia. Nature 421: $639-643$

Dumesic PA, Scholl FA, Barragan DI, Khavari PA (2009) Erk1/2 MAP kinases are required for epidermal G2/M progression. J Cell Biol 185: $409-422$

Ehrenreiter K, Kern F, Velamoor V, Meissl K, Galabova-Kovacs G, Sibilia M, Baccarini M (2009) Raf-1 addiction in Ras-induced skin carcinogenesis. Cancer Cell 16: 149-160

Ehrenreiter K, Piazzolla D, Velamoor V, Sobczak I, Small JV, Takeda J, Leung T, Baccarini M (2005) Raf-1 regulates Rho signaling and cell migration. J Cell Biol 168: 955-964

Flaherty KT, Puzanov I, Kim KB, Ribas A, McArthur GA, Sosman JA, O’Dwyer PJ, Lee RJ, Grippo JF, Nolop K, Chapman PB (2010) Inhibition of mutated, activated BRAF in metastatic melanoma. $N$ Engl J Med 363: $809-819$

Fuchs E (2009) Finding one's niche in the skin. Cell Stem Cell 4: 499-502

Galabova-Kovacs G, Kolbus A, Matzen D, Meissl K, Piazzolla D, Rubiolo C, Steinitz K, Baccarini M (2006a) ERK and beyond: insights from B-Raf and Raf-1 conditional knockouts. Cell Cycle 5: 1514-1518

Galabova-Kovacs G, Matzen D, Piazzolla D, Meissl K, Plyushch T, Chen AP, Silva A, Baccarini M (2006b) Essential role of B-Raf in ERK activation during extraembryonic development. Proc Natl Acad Sci USA 103: $1325-1330$

Gonzalez-Garcia A, Pritchard CA, Paterson HF, Mavria G, Stamp G, Marshall CJ (2005) RalGDS is required for tumor formation in a model of skin carcinogenesis. Cancer Cell 7: 219-226

Gupta S, Ramjaun AR, Haiko P, Wang Y, Warne PH, Nicke B, Nye E, Stamp G, Alitalo K, Downward J (2007) Binding of ras to phosphoinositide 3-kinase p110alpha is required for ras-driven tumorigenesis in mice. Cell 129: $957-968$

Honma M, Benitah SA, Watt FM (2006) Role of LIM kinases in normal and psoriatic human epidermis. Mol Biol Cell 17: 1888-1896

Ise K, Nakamura K, Nakao K, Shimizu S, Harada H, Ichise T, Miyoshi J, Gondo Y, Ishikawa T, Aiba A, Katsuki M (2000) Targeted deletion of the $\mathrm{H}$-ras gene decreases tumor formation in mouse skin carcinogenesis. Oncogene 19: 2951-2956 will increase Rok- $\alpha$ activity and result in epithelial cell differentiation, at least within a window of opportunity. Such a strategy should be useful in the co-therapy of Ras-driven epidermis tumours, much in the way that differentiation therapy has radically increased the success rate of leukaemia treatment (Wang and Chen, 2008).

Janes SM, Watt FM (2006) New roles for integrins in squamous-cell carcinoma. Nat Rev Cancer 6: $175-183$

Karnoub AE, Weinberg RA (2008) Ras oncogenes: split personalities. Nat Rev Mol Cell Biol 9: 517-531

Khavari TA, Rinn J (2007) Ras/Erk MAPK signaling in epidermal homeostasis and neoplasia. Cell Cycle 6: 2928-2931

Lefort K, Mandinova A, Ostano P, Kolev V, Calpini V, Kolfschoten I, Devgan V, Lieb J, Raffoul W, Hohl D, Neel V, Garlick J, Chiorino G, Dotto GP (2007) Notch1 is a p53 target gene involved in human keratinocyte tumor suppression through negative regulation of ROCK1/2 and MRCKalpha kinases. Genes Dev 21: $562-577$

Malliri A, van der Kammen RA, Clark K, van der Valk M, Michiels F, Collard JG (2002) Mice deficient in the Rac activator Tiam1 are resistant to Ras-induced skin tumours. Nature 417: $867-871$

McMullan R, Lax S, Robertson VH, Radford DJ, Broad S, Watt FM, Rowles A, Croft DR, Olson MF, Hotchin NA (2003) Keratinocyte differentiation is regulated by the Rho and ROCK signaling pathway. Curr Biol 13: 2185-2189

Mertens AE, Rygiel TP, Olivo C, van der Kammen R, Collard JG (2005) The Rac activator Tiaml controls tight junction biogenesis in keratinocytes through binding to and activation of the Par polarity complex. J Cell Biol 170: $1029-1037$

Muller EJ, Williamson L, Kolly C, Suter MM (2008) Outside-in signaling through integrins and cadherins: a central mechanism to control epidermal growth and differentiation? J Invest Dermatol 128: 501 - 516

Murayama K, Kimura T, Tarutani M, Tomooka M, Hayashi R, Okabe M, Nishida K, Itami S, Katayama I, Nakano T (2007) Akt activation induces epidermal hyperplasia and proliferation of epidermal progenitors. Oncogene 26: $4882-4888$

Niault T, Sobczak I, Meissl K, Weitsman G, Piazzolla D, Maurer G, Kern F, Ehrenreiter K, Hamerl M, Moarefi I, Leung T, Carugo O, Ng T, Baccarini M (2009) From autoinhibition to inhibition in Trans: the Raf-1 regulatory domain inhibits Rok-alpha kinase activity. J Cell Biol 187: 335-342

Niault TS, Baccarini M (2010) Targets of Raf in tumorigenesis. Carcinogenesis 31: $1165-1174$

Oki-Idouchi CE, Lorenzo PS (2007) Transgenic overexpression of RasGRP1 in mouse epidermis results in spontaneous tumors of the skin. Cancer Res 67: 276-280

Pegtel DM, Ellenbroek SI, Mertens AE, van der Kammen RA, de Rooij J, Collard JG (2007) The Par-Tiam1 complex controls persistent migration by stabilizing microtubule-dependent front-rear polarity. Curr Biol 17: $1623-1634$

Perez-Moreno M, Davis MA, Wong E, Pasolli HA, Reynolds AB, Fuchs E (2006) p120-catenin mediates inflammatory responses in the skin. Cell 124: $631-644$

Riva C, Lavieille JP, Reyt E, Brambilla E, Lunardi J, Brambilla C (1995) Differential c-myc, c-jun, c-raf and p53 expression in squamous cell carcinoma of the head and neck: implication in drug and radioresistance. Eur J Cancer B Oral Oncol 31: 384-391

Rygiel TP, Mertens AE, Strumane K, van der Kammen R, Collard JG (2008) The Rac activator Tiam1 prevents keratinocyte apoptosis by controlling ROS-mediated ERK phosphorylation. J Cell Sci 121: 1183-1192

Scholl FA, Dumesic PA, Barragan DI, Charron J, Khavari PA (2009a) Mek1/2 gene dosage determines tissue response to oncogenic Ras signaling in the skin. Oncogene 28: 1485-1495

Scholl FA, Dumesic PA, Barragan DI, Harada K, Bissonauth V, Charron J, Khavari PA (2007) Mek1/2 MAPK kinases are essential for Mammalian development, homeostasis, and Raf-induced hyperplasia. Dev Cell 12: $615-629$

Scholl FA, Dumesic PA, Barragan DI, Harada K, Charron J, Khavari PA (2009b) Selective role for Mek1 but not Mek2 in the induction of epidermal neoplasia. Cancer Res 69: $3772-3778$ 
Sibilia M, Fleischmann A, Behrens A, Stingl L, Carroll J, Watt FM, Schlessinger J, Wagner EF (2000) The EGF receptor provides an essential survival signal for SOS- dependent skin tumor development. Cell 102: $211-220$

Vasioukhin V, Bauer C, Degenstein L, Wise B, Fuchs E (2001) Hyperproliferation and defects in epithelial polarity upon conditional ablation of alpha-catenin in skin. Cell 104: 605-617

Vitale-Cross L, Amornphimoltham P, Fisher G, Molinolo AA, Gutkind JS (2004) Conditional expression of K-ras in an epithelial compartment that includes the stem cells is sufficient to promote squamous cell carcinogenesis. Cancer Res 64: 8804-8807

Wang Z, Pedersen E, Basse A, Lefever T, Peyrollier K, Kapoor S, Mei Q, Karlsson R, Chrostek-Grashoff A, Brakebusch C (2010) Rac1 is crucial

for Ras-dependent skin tumor formation by controlling Pak1-Mek-Erk hyperactivation and hyperproliferation in vivo. Oncogene 29: 3362-3373 Wang ZY, Chen Z (2008) Acute promyelocytic leukemia: from highly fatal to highly curable. Blood 111: 2505-2515

Wimmer R, Baccarini M (2010) Partner exchange: protein-protein interactions in the Raf pathway. Trends Biochem Sci, e-pub ahead of print 9 July 2010; doi:10.1016/j.tibs.2010.06.001

Yamazaki T, Nakano H, Hayakari M, Tanaka M, Mayama J, Tsuchida S (2004) Differentiation induction of human keratinocytes by phosphatidylethanolamine-binding protein. J Biol Chem 279: 32191-32195

Zaravinos A, Kanellou P, Baritaki S, Bonavida B, Spandidos DA (2009) BRAF and RKIP are significantly decreased in cutaneous squamous cell carcinoma. Cell Cycle 8: 1402-1408 